\title{
Tourism and Gastronomy Management through an Educational Web Platform on Yacuambi of the Province of Zamora Chinchipe - Ecuador.
}

Pablo Alejandro Quezada-Sarmiento ${ }^{1-4+}$, Patricia Marisol Chango-Cañaveral ${ }^{2}$, José Antonio FraizBrea $^{3}$, Karla Mikaela Armijos - Lanchi, Mauricio Patricio Artieda Ponce ${ }^{2}$

${ }^{1}$ Universidad de Valencia -Facultad de Filosofía y Ciencias de la Educación -Programa de Doctorado en Educación, Spain

${ }^{2}$ Universidad Técnica Particular de Loja - Departamento de Ciencias Empresariales

Grupo de Investigación en Observación Turística -Titulación de Gastronomía, Ecuador

${ }^{3}$ Universidad de Vigo - Departamento de Organización de Empresas y Marketing -Facultad de Ciencias Empresariales y Turismo, Spain

${ }^{4}$ Universidad de las Fuerzas Armadas - ESPE- Departamento de Seguridad y Defensa, Ecuador

\begin{abstract}
The use of web, mobile, social media applications are booming in different contexts, especially on education, tourism and gastronomy, since the interaction, generation and rescue of culinary knowledge are the basis to empower a locality in the tourism context. Innovation in tourism products is very important in the communities, some factors that determine it is leadership, management tools, some business processes; theoretically different and seeing innovation as a process, and a result. New technologies and computational paradigms can be used in various fields, including education, tourism and gastronomy which are used for the design, search, presentation, exchange and reuse of material because the technology allows storing, organizing, replicating, disseminating, transforming and be accessible, which leads to saving time and resources. The aim of the article is the development of a web platform for the rescue and promotion of tourism and gastronomy of the Yacuambi, in the context of the Cloud Computing project and teaching computational paradigms on computer engineering curricula.
\end{abstract}

Keywords: Cloud Computing, Education, Tourism, Innovation, Gastronomy, Web Page

\section{Introduction}

Higher educational environments have been subjected in the last decades to a greater pressure for global competitiveness [1 -2], the highest demand of the Society itself regarding their role as social agents and development [3], especially in the context of training computer engineers whose skills must be aligned to the development of technology. the potential of information technologies and communication (ICTs) become a tool strategy for establishing relationships between educational environments, in this case, the University and participation and direct contribution of interest groups.

"Tourism is constituted as the most important economic activity of many developing countries, for this reason it is considered as the driving force of different activities including tourism and gastronomic management" [4]. The use of digital marketing, web applications, social media are booming in different contexts, especially in tourism and gastronomy, since the interaction, generation and rescue of tourism and culinary knowledge are the basis to empower a locality. According to [5] "the main engines of social, economic and environmental development of each of the existing cultures”. It also contributes to the

\footnotetext{
+ Corresponding author. Tel.: + 593 -39806396;

E-mail address: paquesar@alumni.es - paquezada1@espe.edu.ec
} 
improvement and promotion of entrepreneurship in the field of gastronomic tourism, which allows to improve the skills, abilities and knowledge of culinary art, this with the sole objective of providing tourists with a variety of typical dishes, making this activity into an alternative of sustainable economic development providing tourists with a variety

of typical dishes, making this activity into an alternative of sustainable economic development, by improving quality standards in the provision of tourism services and thereby generating greater competitiveness.

Tourism is a possible alternative to leave the site and enter as a protagonist that allows equal conditions for all involved. This, among other reasons, has made community and gastronomic tourism become important in recent years giving way to several countries to include within their public policies, the sustainable tourism development of their territories [6].

Likewise, Ecuadorian gastronomy is one of the fastest growing activities in the creation of foreign exchange for the economic development of the population, as it is the main source of income, both for direct and indirect employment, and for the complementary activities they generate.

Gastronomic tourism has been booming, becoming a business strategy, reducing economic inequalities, which has contributed to the sustainability and development of local economies [7].

Information and communications technologies (ICTs); currently represent tools to support the activities of organizations and allow an optimal and rapid response to the processes of the implanted systems. All economic sectors are currently affected to a greater or lesser extent by ICTs, and the tourism sector is not excluded from the changes that new technologies, so it is intended to enhance tourism through the development of a web portal, social media and digital marketing of the Yacuambi [4].

"One of the ways of knowing the culture and ways of life of a territory is through its gastronomy. Gastronomy represents an important factor within the tourism system, in addition to diversifying the economy by promoting local development, mainly because it involves a wide chain of service providers" [8].One of the important motivations for decision making in a travel offer is its gastronomic offer, especially when it is based on local products that give added value to the product of this, that the promotion through technological means are a contribution to boost the sector tourist.

\section{Methodology}

For the development of this research, it was used as a research methodology Design of Science since it will provide us with a well-defined and documented organized constructivist research process, supported by expected processes and results (artifacts). The Science Design process will include its six phases: identification and motivation of the problem, definition of the objectives of a solution, design and development, demonstration, evaluation and communication. The design of science is an iterative research method based on problem solving. It can also be conceptualized as a Paradigm to create and validate artifacts designed to solve a problem. Artifacts are constructed following existing natural laws and behavioural theories that restrict the Problem mixed with the intuition and other capabilities of researchers. Within the research process based on Science Design, the activities proposed by this methodology were developed, which are described below.

Activity 1. Identification of problems and motivation: In this activity we define the specific research problem and justify the value of a solution on educational context of the used on computational paradigms.

Activity 2: Define the objectives for a solution: The objectives of this research were raised, which were the basis for generating results and artifacts based on science design.

Activity 3: Design and development: In this activity the artifact was developed in this case the website of the Yacuambi town.

Activity 4: Demonstration: The artifact to be developed (web page) tries to resolve the issue of promoting tourism in the Yacuambi town.

Activity 5. Evaluation: The artifact supports a solution to the problem; We compare the objectives of the solution and the actual observed results of the use of the artifact demonstration.

Activity 6: Communication: As a result of the research process a scientific publication will be obtained. 


\subsection{Materials}

For the present investigation, the sample size and the type of random sampling of the different control groups were determined. It was determined with the following formula:

$$
n=\frac{N z^{2} p q}{d^{2}(N-1)+Z^{2} p q}
$$

N Population 448996;

z 95\% confidence level = 1.96;

p Probability of occurrence 0.5 ;

d Margin of error $5 \%=0.05$

\section{Results}

[9] states "that gastronomic tourism is the displacement of visitors, both tourists and hikers, whose main motive is gastronomy, and that it involves practices that range from the displacement of the place of residence to a restaurant to taste a dish". [9] also state that gastronomy is one of the strongest identity traits when it comes to building the image of a tourist destination, that is, it gives way to new trends such as gastronomic tourism. [7] they emphasize web, mobile, social media applications where they are booming in different contexts especially in tourism and gastronomy, giving more knowledge of TICS application ventures that has enhanced the rescue of local gastronomy generating and improving the lifestyle of the communities. Food heritage is part of a new way of conceiving tourism, so these new aspects give way to a new way of conceiving tourism and gastronomic tourism is born that arises from the need to enhance this activity. The design of the website had to be consistent with the content of it. This means that the selection of the type of design that the page has, is consistent with what the user looks for in it and with the service offered by it. For the development of the layout, the contents of the page were first thought and decided, either with paper and pencil or in turn with an application, in this case Adobe Illustrator were used, with it was structured and sketches were made of the sections main, positioning each element of the page on the site that was considered appropriate, and once a sketch of how the web page will be obtained, the graphic part was designed.

To achieve this objective, a methodology to be followed in this project was determined, as follows: Analysis and Planning of the website; The definition and content of the web page; Design and establishment; The implementation and testing; Final acceptance of the project. For the development of the website, the hardware requirements of the application, the server equipment, network requirements were determined if the application was to have an intranet or extranet.

\subsection{Analysis and Planning of the Website}

The first thing that was done when we started working on the project was to perform a basic analysis of the page. This analysis allowed us to know what visitors do on a web page, and with this data we were able to make the best decision to optimize the content and thus determine or choose an agile software for the development of the project; since within that I needed: editors for web designs, web servers, operating systems and other mechanisms that were necessary for development.

It presents step by step how the development of a page was planned and organized, detailing each step raised for the project, starting from an interview with the owners and finally with the completed project.

To develop the website, an interview with the owners was proposed to inform them and detail the objective of the project to be carried out, in order to convey a message to the community and to promote Zamora tourism.

The arguments analyzed in the interview allow us to have a reinforced idea of the following elements:

- Objective. - Determine the objectives of the project, systematically detailing what you want to achieve.

- Audience. - This element is very important since the acceptance of a web page depends on them.

- Technology. - Choose a software that is necessary for the design and development of the page. 


\subsection{Survey of User Requirements}

At this stage, the collaboration of the interested parties was requested with the necessary information to apply in the project, this being a somewhat complex stage. For this project it was necessary to make three visits to the owners, where different fundamental points were established such as the design of the logo and the structure of the Web page since in this way it can obtain functionality and a confluence with the user [10]. All these parameters were presented in the first design sketch that was analyzed by the owners and being corrected in the following visits.

\subsection{Web Design Structure.}

With the information ready for the web and with the structure of the web page, the common properties and validations that have the web forms and menus of options and reports that allowed the interaction between the user and the web page were established, showing in the following. A navigation scheme where the user can travel a route by pressing the buttons where there are different navigation links that were applied on the website.

Next, it is detailed in an illustration referring to the structure of the website built within the framework of the present investigation (Figure 1).

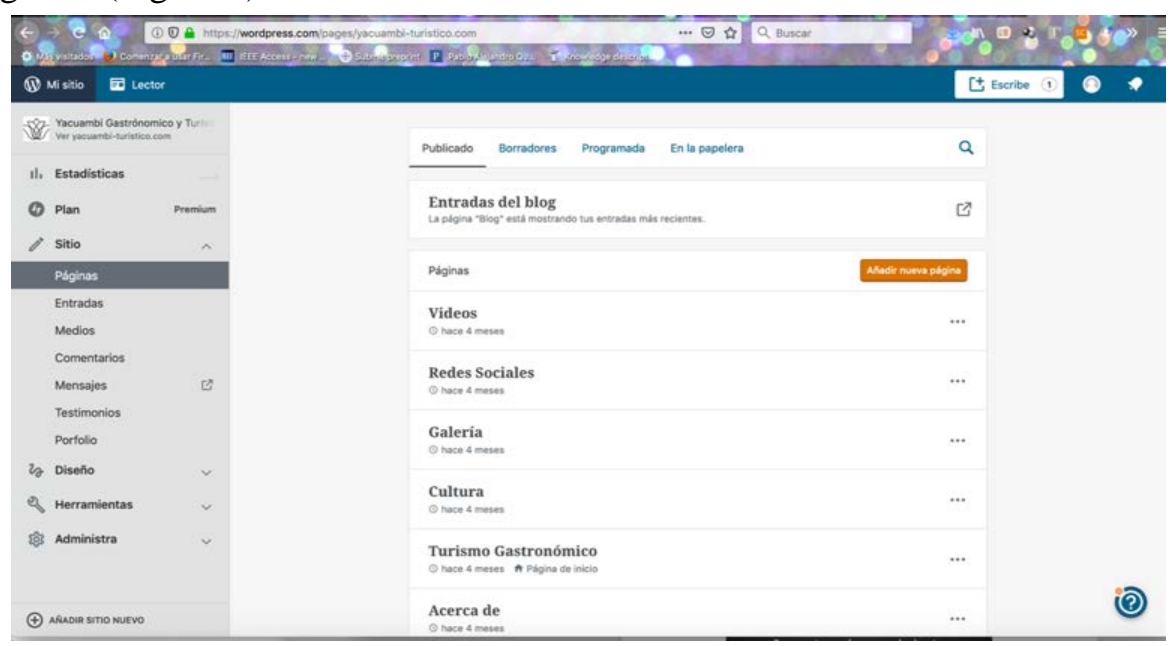

Fig.1: Structure of Web Site www.yacuambi-turistico.com

Figure 2 shows the site implemented in the framework of the proposed project.

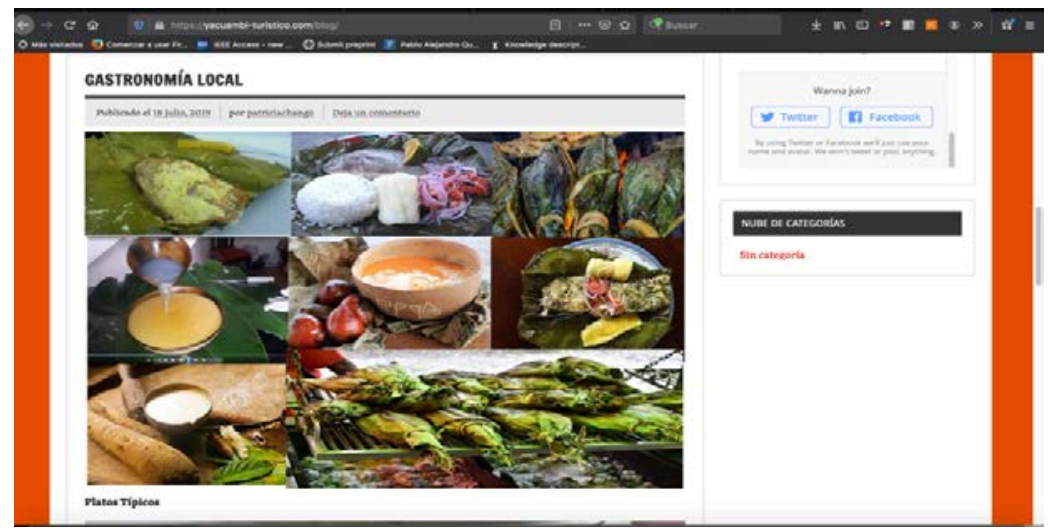

Fig.2: Web Site Yacuambi Turístico

In figure 3 of you can visualize the configuration of the marketing and positioning tools on the web. 


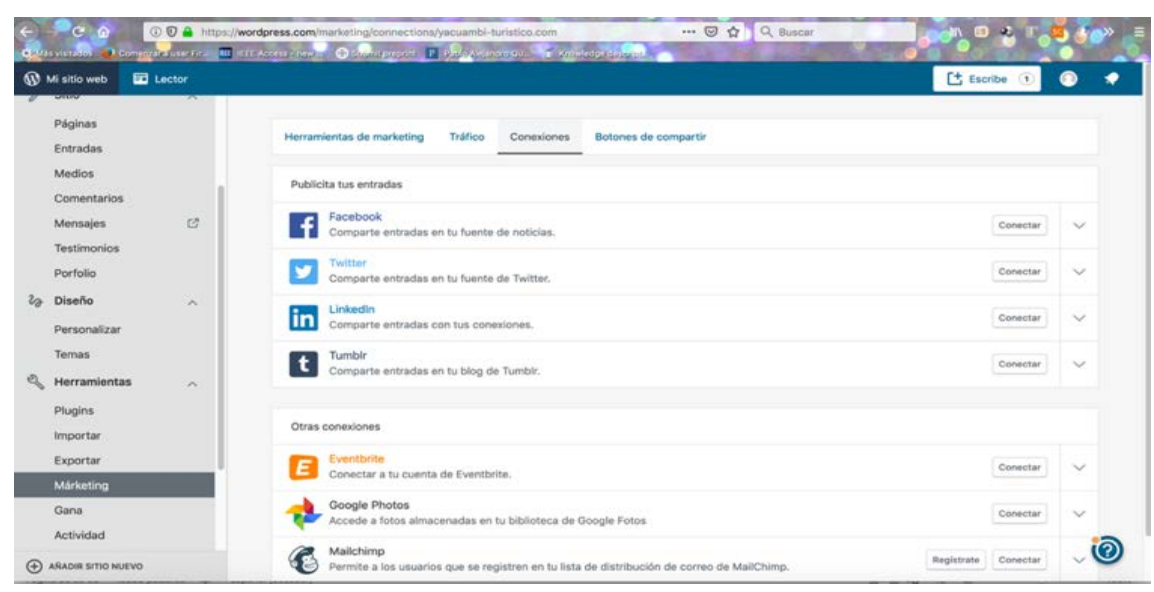

Fig. 3: Marketing and positioning tools on the web.

The network business to tourism companies are the improvement of communications with customers, suppliers and distributors, and the improvement of the corporate image. However, a tourism company can also achieve other significant advantages with the electronic business, which would include promoting products and services, distributing products and managing logistics through the new channel provided by the Internet, marketing through the sale of goods and services, and establish post-sale monitoring via the Internet. One of the main points that a company must consider when positioning on the internet is to establish a communication plan. The objective is to channel, coordinate and supervise the communication and optimal image strategy that must be carried out. In the communication plan they detail, reflect and describe not only the communications, the way of communicating and their strategy, but also the internal and external behavioral protocols. The 2.0 communication plan must cover, among other aspects, some such as identifying, locating and understanding the partners of the organization. The objective is to discover those communities in which you are interested in participating and are a source of potential clients. This requires establishing a series of steps that allow: Identify the tools and actors; Identify the profiles of your interlocutors; Define keywords; Locate contacts on web 2.0 and social networks; Monitor possible network relationships Tourism marketing has changed a lot in recent years, and among those changes we see a trend that leads to the diversification of supply, with the aim of increasing demand. To achieve this challenge, online promotions play an important role in spreading tourist destinations to potential customers.

\section{Conclusions}

In the educational area, the need has been seen to create spaces where they do not exist time and capacity limitations; Thus, education uses various platforms to the teaching-learning process. At the higher education level, especially in the fields of Computer Engineering, the academic world shows an enthusiasm significant for the development of various competencies related to competencies technological the need for the proper use of complementary tools as cloud tools specially focused on improving skills programming that in turn are aligned to the standards or bodies of knowledge that govern these disciplines and the context of affective computing with a real application.

Tourism constitutes the engine of economic and social development for the localities and gives place for visitors to experience and enjoy other ways of living and knowing tourism; among these activities' gastronomy as a cultural factor, through food they can learn about the traditions and culture customs of these localities in such a way that experiential tourism is encouraged that allows tourists to get involved with communities, this type of tourism also fosters respect by nature.

The web applications applied in tourism, at present have become a marketing strategy, to promote tourist destinations and generate through technological resources an increase in the economic scope for entities or people that are linked to the tourism field and gastronomic. Gastronomic tourism based on ICTs is thus presented as a dynamic element of the economy, offering the opportunity to contribute to its development, through the generation of employment and the transversal multiplier effect that originates in other sectors of the social economy. 
To define the business opportunities offered by mobile location services linked to gastronomic tourism, it is necessary to make a careful segmentation of the type of visitor that arrives at the Yacuambi canton. There are niche markets that, without representing a very large number of users, are large potential generators of income to the tourism sector, even more supported by information technologies.

Gastronomy in recent years has become a key element of the tourism sector, since it allows tourists to know products and resources that are native to the area that aim to promote a healthy and sustainable gastronomy from food allowing thus know the culture and customs of the localities.

Yacuambi has a gastronomic and cultural diversity that is sectorized, therefore, there are customs that in some parishes are more marked than in others, the type of custom according to their ethnicity and parish is described as well as it was possible to determine that the canton with its natural attractions and cultural manifestations does not have the proper promotion to highlight its traditions and gastronomy of the sector. Based on technological changes, it can be stated that the tourism industry is currently facing a new environment generated from the transformations to which it has been subjected. This aspect has come to modify the trends of the sector before the demands of a market that requires more personalized and flexible conceptions of the tourist product or service.

\section{References}

[1] SLATER, S.F., HULT, T.M. y OLSON, E.M. (2010) "Factors influencing relative importance of marketing strategy creativity and marketing strategy implementation effectiveness”, Industrial Marketing Management; 39,4: 551-559.

[2] GUMUSLUOGLU, L. e ILSEV, A. (2009) “Transformation leadership creativity, and organizational innovation”, Journal of Business Research; 62, 2: 461-473.

[3] SOLÉ PARELLADA, F. (2004) “Estudio de la relación con la universidad con el sistema productivo español” Programa de Estudio y Análisis destinado a la Mejora de la Calidad en la Enseñanza Superior de la Actividad del Profesorado Universitario - Proyecto EA2004-041, Secretaria del Estado de Educación y Universidades del Ministerio de Educación y Ciencia, Barcelona.

[4] Chango-Cañaveral, P. M., Artieda-Ponce, M. P., Alvarez, W. T. S., \& Quezada-Sarmiento, P. A. (2019). Used of digital marketing for tourism and gastronomic route "mancomunidad bosque seco sabores y tradiciones del sur". Paper presented at the Iberian Conference on Information Systems and Technologies, CISTI, 2019-June doi:10.23919/CISTI.2019.8760868

[5] Suárez-Morales, L., Quezada-Sarmiento, P. A., Guaigua-Vizcaino, M. E., Navas-Alcivar, S. J., \& Rosero-Bustos, M. (2019). The relational marketing and confidence like strategies of the entrepreneurship. Paper presented at the Iberian Conference on Information Systems and Technologies, CISTI, 2019-June doi:10.23919/CISTI.2019.8760976

[6] Quezada-Sarmiento, P. A., Macas-Romero, J. D. C., Roman, C., \& Martin, J. C. (2018). A body of knowledge representation model of ecotourism products in southeastern ecuador. Heliyon, 4(12) doi: 10.1016/j.heliyon. 2018.e01063

[7] Chango-Cañaveral, P. M., Armijos-Nanchi, K. M., Frais-Breas, J. A., Quezada-Sarmiento, P. A., \& BarnuevoSolís, X. A. (2019). Cultural factors linked to the food part of the yacuambi country. Paper presented at the Iberian Conference on Information Systems and Technologies, CISTI, 2019-June doi:10.23919/CISTI.2019.8760754

[8] Armijos .K. (2018). Estudio sobre los factores culturales vinculados a la parte alimentaria del cantón Yacuambi. (Trabajo de Titulación de Ingeniero en Administración de Empresas Turísticas y Hoteleras). UTPL, Loja.

[9] Oliveira, S. (2011). LA GASTRONOMÍA COMO ATRACTIVO TURÍSTICO PRIMARIO DE UN DESTINO. El Turismo Gastronómico en Mealhada - Portugal. Estudios y Perspectivas en Turismo, 20 (3), 738-752.

[10] Quezada-Sarmiento, P. A. (2017). Implementation of a web and mobile solution for vehicular management based on aspects architecture and agile methodologies: An educational approach from theory to practice.

[Implementación de una solución web y móvil para la gestión vehicular basada en Arquitectura de Aspectos y metodologías ágiles: Un enfoque educativo de la teoría a la práctica] RISTI - Revista Iberica De Sistemas e Tecnologias De Informacao, 2017(25), 98-111. doi:10.17013/risti.25.98-111 